\title{
Reseña de Sentencias del Tribunal Constitucional sobre la Administración Local y Autonómica correspondientes al 2002
}

\author{
Francisco Javier Fernández González \\ Director Jurídico Municipal del Ayuntamiento de Santander \\ Profesor Titular de Derecho Administrativo de la Universidad de Oviedo
}

\begin{abstract}
Sumario: I. FUENTES: A) Procedimiento de elaboración de las leyes. B). Imposibilidad de inaplicar una ley vigente sin plantear cuestión de inconstitucionalidad. C) Contenido material de las leyes de presupuestos. II. ADMINISTRACIÓN INSTITUCIONAL Y CORPORATIVA. III. CARGOS PÚBLICOS. IV. EMPLEO PÚBLICO: A) Régimen estatutario de los funcionarios. Retribuciones. Funciones. Régimen disciplinario. B) Derecho a la libertad sindical. V. TUTELA JUDICAL EFECTIVA: A) Derecho a la ejecución de las sentencias y a un proceso sin dilaciones indebidas. B) Derecho a la tutela judicial sin indefensión. Emplazamiento de interesados sobrevenidos. C) Derecho a una sentencia congruente y motivada. D) Derecho al acceso a la justicia y al recurso legal. E) Autorización de entrada en lugar cerrado por un Juzgado penal que interfiere con u contencioso-administrativo pendiente. VI. RECURSO DE AMPARO. INADMISIONES. VII. POLICÍA. VIII. URBANISMO. IX. MEDIO AMBIENTE: A) Espacios naturales protegidos. B) Residuos industriales. C) Caza y pesca de especies protegidas. X. LEYES DE ACOMPAÑAMIENTO. XI. PENSIONES. XII. FORMACIÓN CONTINUA DE TRABAJADORES OCUPADOS.
\end{abstract}

\section{FUENTES}

\section{A) Procedimiento de elaboración de las leyes}

1. de inconstitucionalidad 3492/95 y 3672/95 (acumulados). Promovidos por el Gobierno y el Parlamento de la Comunidad Autónoma de las Illes Balears contra la Ley 26/1995, de 31 de julio, por la que se declara reserva natural las Salinas de Ibiza ("Ses Salines"), las Islas des Freus y las Salinas de Formentera. Oposición del Senado en el procedimiento legislativo.

El Parlamento de las Illes Balears atribuye a la Ley impugnada un defecto formal en su tramitación parlamentaria, consistente en que no se tuvo en cuenta la voluntad del Senado, que expresó su oposición a la proposición de ley remitida por el Congreso al no aprobar el dictamen de la Comisión, lo que, a su juicio, debió dar lugar a una decisión del Pleno del Congreso y no de su Mesa, la cual, sin intervención del Pleno, remitió el texto a la sanción real.

El TC entiende que dado que en la tramitación en el Senado fue rechazado el veto por no haber obtenido mayoría absoluta, sin que tampoco se 
introdujeran enmiendas en el texto del Congreso, al no concurrir el supuesto de hecho exigido por el artículo 90.2 CE para la nueva lectura en el Congreso, se ajustó a la Constitución la decisión adoptada por la Mesa del Congreso.

En relación con la cuestión de fondo vid. apartado relativo a Derecho medioambiental.

(Sentencia n. ${ }^{\circ}$ 97/2002, de 25 de abril de 2002. Sala Primera. BOE 225-2002. Javier Delgado Barrio).

\section{B) Imposibilidad de inaplicar una ley vigente sin plantear cuestión de inconstitucionalidad}

1. Recurso de amparo 3644/99. Promovido por la Generalidad de Cataluña frente a la Sentencia de la Sala de lo Contencioso-Administrativo del Tribunal Superior de Justicia de Cataluña que estimó parcialmente una demanda sobre devolución de ingresos por la tasa fiscal del juego. Sentencia no fundada en Derecho porque inaplica una ley autonómica vigente, que establece un recargo tributario, sin plantear cuestión de inconstitucionalidad. Vulneración del derecho a la tutela judicial efectiva sin indefensión y a un proceso con garantías.

E1 TC entiende que la Sentencia impugnada ha desconocido el principio iura novit curia, al haber estimado la pretensión de nulidad del recargo autonómico por contradicción con la LOFCA, desconociendo, en primer lugar, que la nulidad de dicho recargo sólo puede venir de la previa declaración de inconstitucionalidad de la norma legal que le da cobertura $\mathrm{y}$, en segundo término, cuál es el alcance de su propia jurisdicción. La pretendida nulidad del recargo autonómico por su contradicción con la LOFCA sólo podía ser entendida en términos de constitucionalidad, al tratarse de una supuesta vulneración por una ley autonómica, de una norma integrante del denominado bloque de la constitucionalidad.

La adopción en la Sentencia impugnada de una razón de dar ajena al ámbito jurisdiccional atribuido por el ordenamiento jurídico ha supuesto además, y especialmente, el desconocimiento de las garantías procesales de la recurrente en amparo para hacer valer la constitucionalidad de la Ley del Parlamento de Cataluña 2/1987, de 5 de enero, con infracción del artículo $24 \mathrm{CE}$. 
RESEÑA DE SENTENCIAS DEL TRIBUNAL CONSTITUCIONAL SOBRE LA ADMINISTRACIÓN LOCAL Y AUTONÓMICA...

Fallo: Otorgar el amparo solicitado y, en su virtud:

$1^{\circ}$. Declarar que se ha vulnerado el derecho de la recurrente en amparo a la tutela judicial efectiva sin indefensión y a un proceso con todas las garantías.

$2^{\circ}$. Restablecerla en su derecho y, a tal fin, declarar la nulidad de la Sentencia impugnada, retrotrayendo las actuaciones al momento procesal inmediatamente anterior al de la referida Sentencia, a fin de que se dicte otra nueva Sentencia en la que se respeten los derechos vulnerados.

(Sentencia n. ${ }^{\circ}$ 173/2002, de 9 de octubre de 2002. Sala Segunda. BOE 24-10-2002. Pablo Cachón Villar.)

\section{C) Contenido material de las leyes de presupuestos}

1. Cuestión de inconstitucionalidad 4170/98. Planteada por la Sala de lo Contencioso-Administrativo del Tribunal Superior de Justicia de Cantabria, en relación con el artículo 16.4 de la Ley 53/1984, de 26 de diciembre, de incompatibilidades del personal al servicio de las Administrativos públicas, introducido por la Ley 31/1991, de 30 de diciembre, de Presupuestos Generales del Estado para 1992. Límites constitucionales al contenido material de las leyes de presupuestos. Validez del precepto.

El artículo en cuestión abre la posibilidad a todos los funcionarios públicos de compatibilizar su actividad con el ejercicio de actividades privadas cuando se cumplan los requisitos allí regulados acerca de la cuantía de su complemento específico en relación con sus retribuciones básicas, excluida la antigüedad.

El TC analiza si dicho precepto puede o no conectarse con el llamado contenido eventual o disponible de las Leyes de Presupuestos; es decir, si su regulación sustantiva, aún no siendo estrictamente presupuestaria, se dirige a ordenar la acción y objetivos de la política económica y financiera del sector público estatal, incidiendo en la política de ingresos y gastos del sector público. Y entiende el Alto Tribunal que si bien resulta previsible que el precepto cuestionado no vaya a ser finalmente aplicable a un número elevado de funcionarios, tal apreciación no conduce a privar a aquél de repercusión en los gastos presupuestados, permitiendo, incluso, en determinadas coyunturas, que la oferta pública de empleo incluya un 
espectro significativo de los puestos de tal naturaleza si así resulta necesario, lo que guarda relación directa con las Leyes de Presupuestos.

Fallo: Desestimar la presente cuestión de inconstitucionalidad.

(Sentencia n. ${ }^{\circ}$ 67/2002, de 21 de marzo de 2002. Pleno. BOE 16-42002. Guillermo Jiménez Sánchez. Voto particular formulado por Pablo García Manzano, al que se adhieren Pablo Cachón Villar y Javier Delgado Barrio).

\section{ADMINISTRACIÓN INSTITUCIONAL Y CORPORATIVA}

1. Recursos de inconstitucionalidad 3584/94 y 3592/94, promovidos, respectivamente, por sesenta y dos Senadores pertenecientes al Grupo Parlamentario Popular y por la Junta de Castilla y León contra el Real Decreto-ley 8/1994, de 5 de agosto, por el que se suprimieron como corporaciones de Derecho público las Cámaras Oficiales de la Propiedad Urbana. Decretos-leyes y competencia sobre corporaciones de Derecho público.

El TC declara la validez de los preceptos que suprimen el carácter de corporación pública de las Cámaras (STC 178/1994), someten sus actos a intervención administrativa, y habilitan al Gobierno para reglamentar su personal y patrimonio. El TC entiende que:

- El Decreto-Ley 6/1994 se ha dictado para hacer frente a una situación que cabe calificar razonablemente como «urgente y necesaria».

- Este Decreto-Ley no afecta al régimen de las Comunidades Autónomas, y contiene normativa de carácter básico plenamente conforme con las competencias autonómicas, por un lado, y con los límites temporales y sustantivos que la Constitución impone a los decretos-leyes, por otro.

Fallo: Desestimar los recursos de inconstitucionalidad n. ${ }^{\circ} 3584 / 94$ y $3592 / 94$.

(Sentencia n. ${ }^{\circ}$ 11/2002, de 17 de enero de 2002.Pleno. BOE 8-2-2002. Manuel Jiménez de Parga y Cabrera. Voto concurrente que emite Fernando Garrido Falla y voto particular que suscribe Pablo García Manzano. 
RESEÑA DE SENTENCIAS DEL TRIBUNAL CONSTITUCIONAL SOBRE LA ADMINISTRACIÓN LOCAL Y AUTONÓMICA...

\section{CARGOS PÚBLICOS}

1. Recurso de amparo 1371/98, promovido frente al Decreto de la Presidencia de la Ciudad de Melilla de 12 de marzo de 1998 que inadmitió una moción de censura. Los demandantes de amparo, que en el momento de la interposición del presente recurso eran miembros de la Asamblea de Melilla, alegaban vulneración de los derechos a la participación política. El TC deniega el amparo al haber sido presentado este recurso cuando pendía un contencioso-administrativo igual.

El TC entiende que el mero hecho de que en el momento de la formalización del recurso de amparo estuviera pendiente de decisión un proceso ante un órgano judicial, instado por los mismos demandantes de amparo, con el mismo objeto, y en el que se formulaban las mismas pretensiones que en el proceso constitucional conduce a la inadmisión de éste.

Además, el hecho de que en vía contencioso-administrativa fueron estimadas en su totalidad por Sentencia firme las mismas pretensiones formuladas por los recurrentes en la demanda de amparo, supone que éstos han obtenido la satisfacción procesal de dichas pretensiones, privando así de objeto al recurso de amparo.

Fallo: Denegar el amparo solicitado.

(Sentencia n. ${ }^{\circ}$ 44/2002, de 25 de febrero de 2002. Sala Primera. BOE 3-4-2002. Pablo García Díaz.)

2. Recurso de amparo 3019-2000, promovido frente al Acuerdo de la Mesa del Congreso de los Diputados de 12 de abril de 2000 (confirmado por Acuerdo de 17 de abril de 2000) por el que se denegó la constitución del Grupo Parlamentario Galego (BNG) con Diputados del BNG, PNV y CiU.

Los demandantes de amparo, tres de ellos elegidos Diputados en las candidaturas presentadas por el BNG en las provincias de A Coruña y Pontevedra, y los otros dos en las candidaturas presentadas por el PNV y $\mathrm{CiU}$ en las provincias, respectivamente, de Vizcaya y Barcelona, imputan a los Acuerdos recurridos, en primer término, la lesión de su derecho a acceder en condiciones de igualdad a los cargos y funciones públicos (23.2 CE), en relación con el derecho de los ciudadanos a participar en los asuntos públicos $(23.1 \mathrm{CE})$. 
La interpretación de la Mesa de la Cámara del requisito del inciso segundo del artículo 23.1 del Reglamento del Congreso (exige un $15 \%$ de los votos a cada uno de los Diputados que pretendan constituir Grupo Parlamentario) es de que el porcentaje de votos obtenido por las candidaturas presentadas por una o varias formaciones políticas no puede ser invocado, una vez que algunos Diputados elegidos en aquellas candidaturas lo han utilizado para la constitución de un Grupo Parlamentario, por otros Diputados elegidos en las mismas candidaturas para constituir otro Grupo Parlamentario diferente.

El TC deniega el amparo al entender que la interpretación de la Mesa del Congreso no sólo no es arbitraria, sino que está provista de razonabilidad y encuentra cobertura en y se cohonesta con las previsiones reglamentarias que regulan la constitución de los Grupos Parlamentarios en la Cámara, y no vulnera el artículo 23.2 CE.

Fallo: Desestimar la presente demanda de amparo.

(Sentencia n. ${ }^{0}$ 64/2002, de 11 de marzo de 2002. Sala Segunda. BOE 16-4-2002. Tomás S. Vives Antón).

3. Recurso de amparo 1473-2001. Promovido por el Partido Socialista Obrero Español-Progresistas, frente a la Sentencia de la Sala de lo Contencioso-Administrativo del Tribunal Supremo de fecha 28 de febrero de 2001, sobre el resultado en Asturias de las elecciones generales de 2000.

Los demandantes de amparo invocan una supuesta vulneración de los derechos a la tutela judicial efectiva (acceso a la justicia) y de acceso a los cargos públicos: inadmisión de demanda que pretendía corregir un también supuesto error material fuera de los plazos fijados por la legislación electoral; un error en la transcripción informática de las votaciones que no puede ser corregido fuera de los plazos legales.

El TC deniega el amparo puesto que en el presente caso ni el empleo del cauce para pretender la rectificación del error presuntamente cometido, el del art. 105.2 de la Ley de Procedimiento Común, era posible, ni sobre todo, se accionó a su debido tiempo el derecho que se estimó vulnerado. Según el Alto Tribunal los candidatos y las formaciones políticas que los avalan tienen suficientes posibilidades (claramente en este caso) para llevar a cabo con la diligencia precisa la defensa de sus intereses y con ella la de los intereses objetivos en tiempo y forma. En el presente supuesto no resultó vulnerado ni el derecho a la tutela judicial efectiva ni los derechos del artículo $23 \mathrm{CE}$, 
RESEÑA DE SENTENCIAS DEL TRIBUNAL CONSTITUCIONAL SOBRE LA ADMINISTRACIÓN LOCAL Y AUTONÓMICA...

y en particular el del 23.2 en su contenido de acceso al cargo representativo del recurrente.

Fallo: Denegar el amparo solicitado.

(Sentencia n. ${ }^{\circ} 80 / 2002$, de 8 de abril de 2002. Sala Primera. BOE 25-42002. María Emilia Casas Baamonde).

\section{EMPLEO PÚBLICO}

\section{A) Régimen estatutario de los funcionarios públicos. Retribuciones. Funciones. Régimen disciplinario.}

1. Recurso de inconstitucionalidad 3079/96. Promovido por el Presidente del Gobierno contra el artículo 2.1.a), inciso final y, por conexión, el artículo 1 de la Ley del Principado de Asturias 1/1996, de 26 de abril, de concesión de créditos extraordinarios y suplementos de crédito destinados a atender la actualización de retribuciones, modificación de plantillas y otras obligaciones del personal al servicio de la Administración, Organismos Autónomos y Servicio de Salud del Principado de Asturias. Competencias sobre régimen estatutario de los funcionarios públicos y sobre planificación general de la actividad económica: límites estatales al incremento de retribuciones.

El TC declara la inconstitucionalidad y consiguiente nulidad del artículo 2.1.a) en la parte que destina el suplemento de crédito a lo estipulado para garantizar el mantenimiento del poder adquisitivo en el Acuerdo entre la Administración del Principado y los Sindicatos para el período 1995/1997, puesto que este precepto materializa un incremento en las retribuciones de los empleados públicos autonómicos, a aplicar sobre las retribuciones totales de 1995 con carácter consolidable, que altera la base sobre la que se calcula el posterior incremento del 3,5\% acordado por la Ley 2/1996, de Presupuestos Generales del Principado de Asturias; y dicha alteración perturba la consecución de los objetivos antiinflacionistas perseguidos por el Estado mediante el establecimiento de unos topes a los incrementos retributivos de los empleados del sector público. El TC entiende que la norma autonómica ha de reputarse inconstitucional, no porque ignore esos topes máximos, sino porque modifica la base sobre la que han de computarse.

Fallo: Estimar parcialmente el presente recurso de inconstitucionalidad $y$, en consecuencia: 
$1^{\circ}$. Declarar inconstitucional y nulo el art. 2.1 a), inciso final -que dice «y de lo estipulado para garantizar el mantenimiento del poder adquisitivo en el Acuerdo entre la Administración del Principado y los Sindicatos para el período 1995/1997»- de la Ley del Principado de Asturias impugnada.

$2^{\circ}$. Desestimar el recurso de inconstitucionalidad en todo lo demás.

(Sentencia n. ${ }^{\circ}$ 24/2002, de 31 de enero de 2002. Pleno. BOE 1-3-2002. Pablo Cachón Villar).

2. Cuestiones de inconstitucionalidad acumuladas 71/94 y 243/95. Promovidas por la Sección Primera de la Sala de lo ContenciosoAdministrativo del Tribunal Superior de Justicia de Cataluña en relación con el art. 92.2 de la Ley 7/1985, de 2 de abril, reguladora de las bases del régimen local, y varios artículos de la Ley de Cataluña 17/1985, de 23 de julio, de la función pública de la Administración de la Generalidad. Funciones de los funcionarios públicos y alcance de la reserva de Ley. Sanciones disciplinarias establecidas por una Ley autonómica.

E1 TC entiende que el artículo 92.2 de la LBRL al establecer que también son funciones públicas y, por lo tanto, han de ser desempeñadas por personal funcionario «aquellas que en desarrollo de la presente Ley, se reserven a los funcionarios para la mejor garantía de la objetividad, imparcialidad o independencia en el ejercicio de la función» no vulnera la reserva de ley que establece el artículo 103.3 CE, y, en consecuencia, declara la validez de los preceptos estatales que delimitan los puestos locales reservados a funcionarios.

En relación con varios preceptos de la Ley de Cataluña 17/1985, de la función pública de la Administración de la Generalidad, referidos a diversos aspectos del régimen disciplinario de los funcionarios públicos, el TC declara la validez de los preceptos autonómicos que establecen una falta disciplinaria novedosa, una medida cautelar de traslado, y una sanción de pérdida de grado personal pues entiende que no vulneran el orden constitucional de distribución de competencias, y, en particular los preceptos constitucionales 149.1 .1 y 149.1.18 sobre las bases del régimen estatutario de los funcionarios públicos.

Fallo: Desestimar las presentes cuestiones de inconstitucionalidad.

(Sentencia n. ${ }^{\circ}$ 37/2002, de 14 de febrero de 2002. Pleno. BOE 14-32002. Tomás S. Vives Antón). 
RESEÑA DE SENTENCIAS DEL TRIBUNAL CONSTITUCIONAL SOBRE LA ADMINISTRACIÓN LOCAL Y AUTONÓMICA...

\section{B) Derecho a la libertad sindical}

1. Recurso de amparo 30/99. Promovido frente al Auto de la Sala de lo Social del Tribunal Supremo de 12 de noviembre de 1998, por el que se declara la inadmisión del recurso de casación para la unificación de doctrina interpuesto contra la Sentencia de la Sala de lo Social del Tribunal Superior de Justicia de Andalucia (Sede de Málaga) de 6 de febrero de 1998, asi como frente a esta misma Sentencia, que desestimó una demanda contra el Ayuntamiento de Fuengirola en materia de despido. Vulneración del derecho a la libertad sindical: extinción de los contratos de auxiliares administrativos, en su mayoría afiliados a un sindicato, que no se justifica por causas económicas de reestructuración de plantilla.

El TC entiende que en este supuesto ha quedado acreditada por los trabajadores la existencia de indicios de una actuación empresarial contraria a la libertad sindical (art. 28.1 CE), mientras que por parte del Ayuntamiento empleador no se ha demostrado la existencia de causas objetivas y razonables suficientes que hubieran permitido destruir la apariencia discriminatoria creada y alcanzar la necesaria convicción de que su actuación había sido ajena a todo propósito atentatorio a la libertad sindical. Más aún, el Ayuntamiento ni siquiera ha acreditado la existencia de circunstancias económicas u organizativas objetivas para proceder a la extinción de los contratos de trabajo de los demandantes de amparo.

Fallo: Otorgar el amparo solicitado y, en su virtud:

$1^{\circ}$. Reconocer el derecho de los demandantes a la libertad sindical.

$2^{\circ}$. Anular la Sentencia de la Sala de lo Social del Tribunal Superior de Justicia de Andalucía (sede de Málaga) de 6 de febrero de 1998, recaída en el recurso de suplicación núm. 996/96, lo que implica la firmeza de la Sentencia dictada por el Juzgado de lo Social núm. 1 de Málaga el 28 de diciembre de 1995 en los autos núm. 949-68/95.

(Sentencia n. ${ }^{\circ}$ 48/2002, de 25 de febrero de 2002. Sala Primera. BOE 3.4.2002. Fernando Garrido Falla).

2. Recurso de amparo 809/97. Promovido por la Confederación Sindical Independiente de Funcionarios (CSIF) frente a la Sentencia de la Sala de lo Contencioso-Administrativo del Tribunal Superior de Justicia de Castilla y León, que inadmitió su recurso contra la Diputación Provincial de Burgos sobre adscripción de un funcionario al Patronato de Turismo. Vulneración del derecho a la libertad sindi- 
cal: indicios racionales de discriminación al readscribir el puesto de trabajo de un representante sindical, no justificado por razones de organización de los servicios.

El TC entiende que no queda justificado e la resolución impugnada por qué de ente el personal funcionario de esa Administración fue escogido el puesto de trabajo no singularizado que ocupaba el demandante de amparo para adscribirlo al Patronato de Turismo de la Provincia de Burgos. Y que la única motivación que queda es una genérica invocación a la «satisfacción de las necesidades del servicio, que no puede considerarse suficientemente precisa y detallada como par entender que la Administración haya acreditado la existencia de causas reales, absolutamente extrañas a la pretendida vulneración de derechos fundamentales con entidad suficiente para justificar concretamente la decisión adoptada.

Fallo: Estimar el recurso de amparo promovido por la Confederación Sindical Independiente de Funcionarios y, en consecuencia:

$1^{\circ}$. Reconocer el derecho fundamental de la demandante a la libertad sindical (art. 28.1 CE).

$2^{\circ}$. Declarar la nulidad del Decreto núm. 3621 del Presidente de la Diputación Provincial de Burgos, de 27 de noviembre de 1995, por el que se resuelve adscribir el puesto de trabajo no singularizado de que es titular el demandante de amparo en la Unidad de Cultura, Educación y Turismo, al Patronato de Turismo de la Provincia de Burgos.

(Sentencia n. ${ }^{\circ}$ 114/2002, de 20 de mayo de 2002.Sala Primera. BOE 196-2002. Javier Delgado Barrio).

\section{TUTELA JUDICIAL EFECTIVA}

\section{A) Derecho a la ejecución de las sentencias y a un proceso sin dilaciones indebidas}

1. Recurso de amparo 4338/99. Promovido frente a las resoluciones de la Sala de lo Contencioso-Administrativo del Tribunal Superior de Justicia de Galicia, Sección Primera, dictadas en ejecución de una Sentencia de dicha Sala, de 23 de abril, sobre provisión de puestos de trabajo en la Xunta de Galicia. Alegada vulneración del derecho a la tutela judicial efectiva (en la ejecución de Sentencia), y vulneración del derecho a un proceso sin dilaciones indebidas el TC 
RESEÑA DE SENTENCIAS DEL TRIBUNAL CONSTITUCIONAL SOBRE LA ADMINISTRACIÓN LOCAL Y AUTONÓMICA...

aprecia una actitud pasiva de la Administración al ejecutar una Sentencia que anuló un requisito de una convocatoria de puestos, cubiertos años antes.

El recurrente había presentado a requerimiento del órgano judicial varias propuestas de ejecución de sentencia mediante la asignación de puestos de trabajo singularizados, y a dichas propuestas la Administración respondía con denegaciones motivadas, pero no con propuestas propias, por lo que el TC entiende que es la actitud pasiva de la Xunta de Galicia el factor que provoca la repetición de una misma secuencia contradictoria en el incidente de ejecución, y que dicha secuencia dilatoria ha sido tolerada por el órgano judicial, lo que lleva a concluir que el recurrente ha sido lesionado en su derecho a no sufrir dilaciones indebidas en ejecución de sentencias.

Fallo: Estimar parcialmente el presente recurso de amparo y, en consecuencia:

$1^{\circ}$. Declarar que ha sido vulnerado el derecho fundamental del demandante a un proceso sin dilaciones indebidas en la ejecución de la Sentencia impugnada.

$2^{\circ}$. Restablecer al recurrente en el disfrute de su derecho, y a tal fin ordenar que se adopten las medidas pertinentes para poner fin a las dilaciones en el ejecución de la referida Sentencia.

$3^{\circ}$. Denegar el amparo en todo lo demás.

(Sentencia n. ${ }^{\circ} 7 / 2002$, de 14 de enero de 2002. Sala Segunda. BOE 82-2002. Guillermo Jiménez Sánchez).

2. Recurso de amparo 3704-2000. Promovido, respecto a los Autos de la Sala de lo Contencioso-Administrativo del Tribunal Superior de Justicia de Cataluña que revocaron la compensación de tributos acordada en ejecución de una Sentencia de 1997 sobre devolución de ingresos por la tasa fiscal del juego de 1991. Vulneración del derecho a la tutela judicial efectiva respecto de los derechos a la intangibilidad de las resoluciones judiciales firmes y a la ejecución de lo resuelto en sus propios términos. Fallo sobre un ejercicio tributario, cuya ejecución se refiere a otro año distinto: Declarada la nulidad de las autoliquidaciones correspondientes al ejercicio de 1991, los Autos en cuestión declaran que realmente lo impugnado era el ejercicio de 1990. 
Las resoluciones impugnadas no sólo han alterado el sentido de la decisión adoptada en una Sentencia firme, vulnerando el derecho a la intangibilidad de las resoluciones judiciales firmes, sino que, además, han impedido la ejecución de lo resuelto en sus propios términos, lesionando, con ello el derecho a la tutela judicial efectiva del recurrente en amparo.

Fallo: Otorgar el amparo solicitado, y, en su virtud:

$1^{\circ}$. Declarar que se ha vulnerado el derecho de la recurrente en amparo a la tutela judicial efectiva, en su vertiente de derecho a la intangibilidad de las resoluciones judiciales firmes y a la ejecución de las sentencias en sus propios términos (art. 24.1 CE).

$2^{\circ}$. Restablecer a la entidad recurrente en su derecho y, a tal fin, declarar la nulidad de los Autos impugnados.

$3^{\circ}$. Retrotraer las actuaciones al momento procesal inmediatamente anterior al de los referidos Autos para que se proceda a la ejecución de la Sentencia en sus propios términos.

(Sentencia n..$^{\circ}$ 175/2002, de 9 de octubre de 2002. Sala Segunda. BOE 24-10-2002. Tomás S.Vives Antón).

\section{B) Derecho a la tutela judicial sin indefensión. Emplazamiento de interesados sobrevenidos}

1. Recurso de amparo 4138/98 y $4167 / 98$ (acumulados). Promovidos frente a las Sentencias de las Salas de lo Contencioso-Administrativo del Tribunal Supremo (de 22 de diciembre de 1997) y del Tribunal Superior de Justicia de Cantabria (de 16 de octubre de 1992) que anularon la licencia de obra otorgada por el Ayuntamiento de Santander para construir diez viviendas unifamiliares. Supuesta vulneración del derecho a la tutela judicial sin indefensión: emplazamiento de interesados sobrevenidos, al adquirir las viviendas en litigio.

El TC deniega el amparo al entender que la actuación de los órganos judiciales que dictaron las Sentencias recurridas ha sido, no sólo procesalmente correcta, sino incontestable desde la perspectiva de la tutela judicial, puesto que en el presente caso no constaba en el expediente administrativo ninguna referencia a los ahora recurrentes, ni tampoco existía esa referencia cuando se inicia el proceso judicial. Para que la falta de emplazamiento tenga relevancia constitucional debe cumplirse el 
RESEÑA DE SENTENCIAS DEL TRIBUNAL CONSTITUCIONAL SOBRE LA ADMINISTRACIÓN LOCAL Y AUTONÓMICA...

requisito de que el interesado sea identificable por el órgano jurisdiccional, lo que depende esencialmente de la información contenida en el escrito de interposición del recurso, en el expediente administrativo o en la demanda.

Fallo: Denegar el amparo solicitado.

(Sentencia n. ${ }^{\circ}$ 18/2002, de 28 de enero de 2002. Sala Segunda. BOE. 82-2002. Elisa Pérez Vera).

\section{C) Derecho a una Sentencia congruente y motivada}

2. Recurso de amparo 243/2000. Promovido frente a la Sentencia de 9 de septiembre de 1999 del Juzgado de lo Contencioso-Administrativo núm. 1 de Córdoba que desestimó la demanda contra el Ayuntamiento en relación con una denegación de la autorización para proceder a canalizar el cableado necesario para una televisión local. Vulneración del derecho a la tutela judicial efectiva por incongruencia y falta de motivación: Sentencia que no da respuesta a la cuestión de si se ha aplicado retroactivamente una legislación restrictiva de derechos, y que no motiva la negativa a plantear cuestión de inconstitucionalidad.

El TC entiende que existe incongruencia omisiva o ex silentio puesto que el demandante pretendió, como cuestión concreta que funda su demanda contencioso-administrativa, la anulación del acto impugnado denegatorio por vulneración del artículo $9.3 \mathrm{CE}$, al aplicar con carácter retroactivo una legislación restrictiva de derechos individuales (en concreto la Ley 42/1995, de 22 de diciembre, de las telecomunicaciones por cable), vulnerando así sus derechos adquiridos, y esta pretensión no encontró respuesta alguna en la fundamentación de la Sentencia.

Por otra parte, el Juez no exteriorizó razonamiento alguno para justificar su decisión de no plantear la cuestión de inconstitucionalidad instada por la parte demandante, por lo que también se infringió su derecho a una tutela judicial efectiva sin indefensión (artículo 24.1 CE).

Fallo: Otorgar el amparo solicitado, y, en consecuencia:

$1^{\circ}$. Declarar el derecho de la sociedad demandante a una tutela judicial efectiva sin indefensión (art. 24.1. CE).

$2^{\circ}$. Anular la Sentencia y el Auto impugnados. 
$3^{\circ}$. Retrotraer las actuaciones procesales al momento inmediato anterior al de dicha Sentencia, a fin de que por el mencionado Juzgado se pronuncie, con plenitud de jurisdicción, nueva Sentencia con respeto del derecho fundamental reconocido.

(Sentencia n. ${ }^{\circ}$ 35/2002, de 11 de febrero de 2002. Sala Primera. BOE 14-3-2002. María Emilia Casas Baamonde).

\section{D) Derecho al acceso a la justicia y al recurso legal}

1. Recurso de amparo 5208/98. Promovido frente a los Autos de las Salas de lo Contencioso-Administrativo del Tribunal Supremo y del Tribunal Superior de Justicia de Cantabria que inadmitieron un recurso contra el Ayuntamiento de Campoo de Yuso, sobre demolición de obras. Supuesta vulneración del derecho a la tutela judicial efectiva en relación con el acceso a la justicia y al recurso legal: inadmisión de demanda contra acto administrativo que reproduce un acto anterior firme y consentido; cuantía del recurso de casación.

Los Autos de inadmisión del TSJ apreciaban la concurrencia de la causa de inadmisibilidad enunciada en el art. 40 a) LJCA de 1956, pues a juicio del órgano judicial, la resolución municipal impugnada (de 9 de abril de 1996) era reproducción de un acto administrativo anterior firme (el Decreto del Alcalde de 12 de diciembre de 1995) por el que se ordenaba la demolición de lo indebidamente construido. El recurrente aludía a que el primer acto administrativo le fue comunicado sólo en forma verbal y no con las garantías del art. 59 LPC, pero en forma alguna justificó que el órgano judicial haya ejercido su función jurisdiccional impidiendo el pleno disfrute del derecho de acceso a la jurisdicción contenido en el art. 24.1 CE, y por ello deniega el amparo en este punto.

Respecto del auto de inadmisión del TS también deniega el amparo pues al determinar el órgano judicial la cuantía del asunto por referencia al proyecto de obra autorizado en la licencia municipal en forma alguna se puede concluir que la determinación de la cuantía contenga un error patente y relevante ex art. 24.1 CE.

Fallo: Denegar el amparo pedido.

(Sentencia n. ${ }^{\circ}$ 60/2002, de 11 de marzo de 2002. Sala Primera. BOE 164-2002. Roberto García-Calvo y Montiel). 
RESEÑA DE SENTENCIAS DEL TRIBUNAL CONSTITUCIONAL SOBRE LA ADMINISTRACIÓN LOCAL Y AUTONÓMICA...

2. Recurso de amparo 3544/97. Promovido frente a los Autos de la Sala de lo Contencioso-Administrativo del Tribunal Superior de Justicia de Madrid, que inadmitieron una demanda contra la Consejería de Medio Ambiente y Desarrollo Regional de la Comunidad de Madrid. Vulneración del derecho a la tutela judicial efectiva en su manifestación de acceso a la jurisdicción: demanda que acumula un recurso de amparo judicial y un recurso ordinario.

El recurrente, aunque no lo manifestara expresamente en su escrito de interposición, estaba interponiendo en un mismo escrito dos recursos distintos. Esta no es la única interpretación posible y por ello, no puede considerarse que la Sala al entender que el recurrente había interpuesto únicamente el recurso especial que preveía la Ley 62/78 (e inadmitirlo por extemporáneo) haya efectuado una interpretación arbitraria ni irrazonable de su escrito de interposición de recurso. Ahora bien, tal interpretación es excesivamente formalista y por este motivo, al privar al recurrente en amparo del acceso a la jurisdicción, ha lesionado su derecho fundamental a la tutela judicial efectiva.

Fallo: Otorgar el amparo solicitado y, en consecuencia:

$1^{\circ}$. Reconocer que al recurrente en amparo se le ha vulnerado su derecho fundamental a la tutela judicial efectiva en su manifestación de derecho de acceso a la jurisdicción.

$2^{\circ}$. Restablecerle en su derecho y, a tal fin, anular los Autos impugnados.

$3^{\circ}$. Retrotraer las actuaciones al momento anterior en que fue dictada la primera de las resoluciones anuladas con el fin de que la Sala dicte otra que sea conforme con el derecho fundamental que consagra el art. 24.1 CE.

(Sentencia n. ${ }^{0}$ 72/2002, de 8 de abril de 2002. Sala Segunda. BOE 254-2002. Eugeni Gay Montalvo).

3. Recurso de amparo 2330/99. Promovido frente al Auto de la Sala Tercera del Tribunal Supremo que confirmó la denegación de la preparación de su recurso de casación en un contencioso contra la Consejería de Agricultura y Comercio de la Junta de Extremadura sobre adjudicación de una vivienda. Supuesta vulneración del derecho a la tutela judicial efectiva en su manifestación de acceso al recurso legal; inadmisión de recurso de casación por no justificar la infracción de una norma no autonómica tras la sucesión de Administraciones públicas. 
El TC entiende que el Auto del TS recurrido en amparo no incurre en arbitrariedad o irrazonabilidad al aplicar los artículos 93.4 y 96.2 de la LJCA de 1956 y considerar que el acto administrativo recurrido procedía de un órgano de la Comunidad Autónoma de Extremadura, pese a que la adjudicación de la vivienda que en definitiva se recurría en vía contencioso-administrativa había sido realizada por el IRYDA antes de que se produjese la transferencia a la Comunidad Autónoma de las competencias ejercidas por tal organismo.

Fallo: Desestimar el recurso de amparo.

(Sentencia n. ${ }^{\circ}$ 89/2002, de 22 de abril de 2002. Sala Segunda. BOE 225-2002. Guillermo Jiménez Sánchez.)

4. Recurso de amparo 4834-2000. Promovido frente al Auto de la Audiencia Provincial de Sevilla que denegó la personación de los acogedores preadoptivos en un litigio entre la madre biológica de unos menores y la Junta de Andalucía. Vulneración del derecho a la tutela judicial efectiva en su vertiente de acceso al proceso: personación de los acogedores preadoptivos de menores en un procedimiento sobre desamparo y acogimiento familiar.

El TC entiende que los demandantes de amparo, en su condición de acogedores preadoptivos de los dos menores, son titulares de un interés legítimo, que les permitía ex art. 24.1 CE, comparecer y ser oídos en el procedimiento a quo, y que los motivos en los que la Audiencia Provincial fundó su decisión de denegarles la personación solicitada no satisfacen las exigencias de razonabilidad y proporcionalidad, que pudieran justificar la restricción del derecho fundamental que se sacrifica.

Fallo: Estimar la presente demanda de amparo y, en su virtud,

$1^{\circ}$. Declarar que se ha vulnerado a los demandantes de amparo su derecho a la tutela judicial efectiva.

$2^{\circ}$. Restablecerles en su derecho y, a tal fin, declarar la nulidad de los Autos impugnados, retrotrayendo las actuaciones judiciales al momento procesal y con los efectos señalados en el fundamento jurídico octavo de esta Sentencia.

(Sentencia n. ${ }^{\circ}$ 124/2002, de 20 de mayo de 2002. Sala Segunda. BOE 19-6-2002. Vicente Conde Martín de Hijas).

5. Recurso de amparo 224-2002. Promovido frente a la Sentencia de la Sala de lo Contencioso-Administrativo, Sección Primera, del Tribu- 
RESEÑA DE SENTENCIAS DEL TRIBUNAL CONSTITUCIONAL SOBRE LA ADMINISTRACIÓN LOCAL Y AUTONÓMICA...

nal Superior de Justicia de Andalucía (Sede de Sevilla), de 27 de septiembre de 1999, que inadmitió su demanda contra la Junta de Andalucía sobre concurso para la adquisición de la condición de Catedrático, así como contra las Ordenes de 13 de diciembre de 1995 y 17 de febrero de 1997 de la Consejería de Educación de la Junta de Andalucía que resolvieron un concurso de méritos para la adquisición de la condición de Catedrático, en las que no fue seleccionado para ella. Vulneración del derecho a la tutela judicial efectiva en su vertiente de acceso a la justicia.

El TC entiende que se ha producido una vulneración del derecho a la tutela judicial efectiva (acceso a la justicia) puesto que se privó al recurrente de una Sentencia sobre el fondo de sus pretensiones, relacionadas con la adecuación de unos méritos a las normas de la convocatoria, mediante la aplicación desproporcionada de la inadmisión de un recurso contencioso-administrativo por acto firme y consentido. La Sentencia del TSJ había inadmitido el recurso al considerar como actos firmes y consentidos Ordenes de la Consejería de Educación conforme a las cuales el demandante de amparo había sido seleccionado, por lo que el carácter de acto firme y consentido que se predica por el Tribunal sentenciador de dichas órdenes resulta contrario al artículo 24.1 CE pues la exigencia de impugnar unos listados que en nada le perjudicaban forzosamente tiene que considerarse exorbitante.

Fallo: Estimar parcialmente el recurso de amparo y, en consecuencia:

$1^{\circ}$. Declarar que ha sido vulnerado el derecho fundamental del recurrente a la tutela judicial efectiva.

$2^{\circ}$. Restablecer al recurrente en la integridad de su derecho y, a tal fin, declarar la nulidad de la Sentencia impugnada y reconocer el derecho del demandante de amparo a que el recurso contencioso-administrativo $\mathrm{n}^{\circ}$ 419/1996 no sea declarado inadmisible por aplicación de la causa de inadmisión aquí cuestionada, retrotrayendo, en consecuencia, las actuaciones al momento procesal oportuno para que se adopte la resolución adecuada a efectos de respetar el derecho fundamental vulnerado.

$3^{\circ}$. Desestimar el recurso en todo lo demás.

(Sentencia n. ${ }^{\circ}$ 143/2002, de 17 de junio de 2002. Sala Segunda. BOE 18-6-2002. Guillermo Jiménez Sánchez.).

6. Recurso de amparo 6868-2000. Promovido frente a las resoluciones del Juzgado de lo Contencioso-Administrativo de Santa Cruz de 
Tenerife y del Tribunal Superior de Justicia de Canarias, que inadmitieron su demanda contra el Cabildo Insular de Tenerife sobre sanción urbanística. Supuesta vulneración del derecho a la tutela judicial efectiva en su vertiente de acceso a la justicia: inadmisión de recurso contencioso-administrativo por insuficiencia del poder de representación procesal, que no fue subsanada.

El TC pone de manifiesto como las resoluciones impugnadas han permitido la subsanación de un defecto procesal advertido en dos ocasiones a la defensa de la recurrente, por lo que concluye que el archivo del recurso no vulneró su derecho a la tutela judicial efectiva que, en ningún caso puede amparar actitudes carentes de la diligencia debida por parte del interesado.

Fallo: Denegar el amparo solicitado.

(Sentencia n. ${ }^{\circ}$ 153/2002, de 15 de julio, de 2002. Sala Primera. BOE $7-$ 8-2002. María Emilia Casas Baamonde).

7. Recurso de amparo 5322-2000. Promovido por la Comunidad de Madrid frente a la Sentencia de la Sala de lo Contencioso-Administrativo del Tribunal Superior de Justicia que inadmitió su demanda contra el Tribunal Económico-Administrativo Regional por el impuesto sobre transmisiones patrimoniales y actos jurídicos documentados derivado de la venta de una vivienda. Vulneración del derecho a la tutela judicial efectiva en su vertiente de acceso a la justicia: derechos fundamentales de los entes públicos; legitimación de una Comunidad Autónoma para impugnar resoluciones de los Tribunales económico-administrativos sobre gestión de tributos cedidos.

La resolución judicial impugnada inadmitió por falta de legitimación activa el recurso contencioso-administrativo interpuesto por la Comunidad Autónoma recurrente contra la Resolución del Tribunal EconómicoAdministrativo Regional de Madrid.

El TC entiende que la Sentencia impugnada no supera el juicio de constitucionalidad por haber limitado el acceso a la jurisdicción de la Administración demandante de amparo, mediante una interpretación de la legalidad, no sólo contraria al orden competencial derivado de la Constitución, sino en exceso rigurosa y, en consecuencia, lesiva del principio pro actione, lo que ha vulnerado el derecho a la tutela judicial efectiva de la recurrente, en su derecho de acceso al proceso. 
RESEÑA DE SENTENCIAS DEL TRIBUNAL CONSTITUCIONAL SOBRE LA ADMINISTRACIÓN LOCAL Y AUTONÓMICA...

Fallo: Otorgar el amparo solicitado, y, en su virtud:

$1^{\circ}$. Declarar que se ha vulnerado el derecho de la recurrente en amparo a la tutela judicial efectiva, en su vertiente de derecho de acceso a la jurisdicción.

$2^{\circ}$. Restablecerla en su derecho y, a tal fin, declarar la nulidad de la Sentencia impugnada.

$3^{\circ}$. Retrotraer las actuaciones al momento procesal inmediatamente anterior al de la referida Sentencia, a fin de que se respete el derecho lesionado.

(Sentencia n. ${ }^{\circ}$ 176/2002, de 9 de octubre de 2002. Sala Segunda. BOE 24-10-2002. Vicente Conde Martín de Hijas).

8. Recurso de amparo 5321-2000. Promovido por la Comunidad de Madrid frente a la Sentencia de la Sala de lo Contencioso-Administrativo del Tribunal Superior de Justicia de Madrid que inadmitió su demanda contra el Tribunal Económico-Administrativo Regional por el impuesto sobre transmisiones patrimoniales y actos jurídicos documentados derivado de la venta de una vivienda. Vulneración del derecho a la tutela judicial efectiva en su vertiente de acceso a la justicia: STC 176/2002.

El TC estima el recurso aplicando la doctrina dictada en su Sentencia 176/2002 (vid. supra).

Fallo: Otorgar el amparo solicitado por la Comunidad de Madrid y, en su virtud:

$1^{\circ}$. Reconocer el derecho de la recurrente en amparo a la tutela judicial efectiva, en su vertiente de derecho de acceso a la jurisdicción (art. 24.1 CE).

$2^{\circ}$. Anular la Sentencia impugnada.

$3^{\circ}$. Retrotraer las actuaciones al momento procesal inmediatamente anterior al de la referida Sentencia a fin de que se respete el derecho con el contenido constitucionalmente declarado.

(Sentencia n. ${ }^{\circ}$ 201/2002, de 28 de octubre de 2002. Sala Primera. BOE 20-11-2002. María Emilia Casas Baamonde).

9. Recurso de amparo 5920-2000. Promovido por la Confederación Sindical de Comisiones Obreras (Unión Regional de Castilla y 
León) frente a la Sentencia de la Sala de lo Contencioso-Administrativo del Tribunal Superior de Justicia de Castilla y León, con sede en Valladolid, de 28 de septiembre de 2000, que, en apelación, inadmitió su recurso contra un Acuerdo de la Diputación de Zamora por el que se reconocía, de forma provisional y transitoria, la compatibilidad para el ejercicio de actividades en el sector privado a 16 médicos, funcionarios adscritos al Hospital Provincial de Zamora. Vulneración del derecho a la tutela judicial efectiva en su vertiente de acceso a la justicia: inadmisión de recurso contencioso-administrativo por falta de legitimación del sindicato, ignorando su legítimo interés profesional o económico.

El TC entiende que la Sentencia objeto de este proceso de amparo denegó la legitimación procesal del sindicato al no considerar acreditado el interés profesional o económico exigido, realizando una interpretación del interés legítimo excesivamente rigorista, desproporcionada y contraria al principio pro actione, lo cual entrañó una lesión del derecho a la tutela judicial efectiva en su vertiente de derecho a acceso a la jurisdicción.

Fallo: Otorgar el amparo solicitado, y, en su virtud:

$1^{\text {o }}$. Reconocer el derecho a la tutela judicial efectiva del sindicato.

$2^{\circ}$. Anular la Sentencia impugnada.

$3^{\circ}$. Retrotraer las actuaciones al momento de dictar Sentencia para que la Sala, reconocida la legitimación activa del sindicato, dicte la resolución que proceda con plenitud de jurisdicción.

(Sentencia n. ${ }^{\circ}$ 203/2002, de 28 de octubre de 2002. Sala Primera. BOE 20-11-2002. María Emilia Casas Baamonde).

10. Recurso de amparo 2885/99. Promovido frente al Auto de un Juzgado de lo Contencioso-Administrativo de Madrid que le tuvo por desistido en su demanda contra el Ayuntamiento de Madrid por infracciones de tráfico. Vulneración del derecho a la tutela judicial efectiva en su manifestación de acceso a la justicia: inadmisión de demanda por no aceptar la sustitución del Procurador, ni permitir subsanar la falta de acreditación de justa causa.

El Auto impugnado tuvo por desistido al demandante al considerar que el actor no compareció en el acto de la vista, por el hecho de que al mismo concurrió un Procurador distinto del que tenía otorgada su representación apud acta, sin justificar la sustitución. El TC entiende que atendiendo a la 
naturaleza del defecto procesal resultaba inexcusable el trámite de subsanación, máxime si se tiene en cuenta que ni siquiera consistió en falta de intervención de Procurador-supuesto en el que también habría sido necesario tal trámite-, sino sólo en la deficiente justificación del presupuesto habilitante de la sustitución del Procurador realizado en el acto de la vista.

Fallo: Estimar el recurso de amparo interpuesto, y, en su virtud:

$1^{\circ}$. Declarar que se ha vulnerado el derecho del recurrente a la tutela judicial efectiva (art. 24.1 CE).

$2^{\circ}$. Restablecerle en el citado derecho y, a tal fin, anular los Autos impugnados, retrotrayendo las actuaciones al momento de celebración de la vista, para que por el citado órgano judicial se conceda al demandante de amparo un trámite para subsanar el defecto advertido en la sustitución de su Procuradora en dicho acto.

(Sentencia n. ${ }^{\circ}$ 206/2002, de 11 de noviembre de 2002. Sala Segunda. BOE 29-11-2002. Elisa Pérez Vera. )

11. Recurso de amparo 4353-2001. Promovido frente a la Sentencia de un Juzgado de lo Social de Jaén que desestimó la demanda contra la Delegación de Gobierno de la Consejería de Gobernación de la Junta de Andalucía por modificaciones sustanciales de las condiciones de trabajo. Vulneración del derecho a la tutela judicial efectiva en su vertiente de acceso a la jurisdicción: inadmisión de demanda social por caducidad, al haber transcurrido el plazo legal de veinte días, a pesar de haber sido interpuesta dentro del plazo de dos meses indicado erróneamente por la Administración.

El TC entiende que la prevalencia que el Juzgado de lo Social ha concedido al artículo 59 LET frente al art. 58.2 y 3 LPC supone de hecho, que la Administración se haya beneficiado de sus propias irregularidades, dado que ha inducido a la demandante de amparo a error, y a actuar dentro de un plazo, que posteriormente la misma Administración consideró inaplicable, y en el que fundó la excepción de caducidad alegada en el acto del juicio. Por ello concluye que la interpretación de los requisitos de admisibilidad de la demanda efectuada por el órgano jurisdiccional ha vulnerado el artículo 24.2 CE.

Fallo: Estimar la presente demanda de amparo, y, en su virtud:

$1^{\circ}$. Declarar vulnerado el derecho de la recurrente a la tutela judicial efectiva (art. 24.1 CE) en su vertiente de acceso a la jurisdicción. 
$2^{\circ}$ Restablecerla en su derecho y, a tal fin, anular la Sentencia impugnada, retrotrayendo las actuaciones al momento inmediatamente anterior al de dictarse la mencionada Sentencia, a fin de que se dicte una nueva Sentencia respetuosa con el derecho fundamental vulnerado.

(Sentencia n. ${ }^{\circ}$ 214/2002, de 11 de noviembre de 2002. Sala Segunda. BOE 29-11-2002. Vicente Conde Martín de Hijas).

12. Recurso de amparo 6305-2001. Promovido frente a la Sentencia de la Sala de lo Contencioso-Administrativo del Tribunal Superior de Justicia de Castilla y León que desestimó su demanda contra el Ayuntamiento de Venta de Baños, sobre acceso de la Tesorería al programa informático contable. Vulneración del derecho a la tutela judicial efectiva en su vertiente de acceso a la justicia: inadmisión de demanda por falta de postulación, apreciada en grado de apelación de un procedimiento abreviado sin posibilidad de subsanarla.

La Sentencia impugnada inadmitió el recurso de apelación interpuesto por la demandante de amparo puesto que, a diferencia de lo apreciado por el Juez, entendió que en el proceso se suscitaba una cuestión que no podía calificarse como de personal y que, por ello, la condición de funcionaria de la demandante no la habilitaba para comparecer por sí, sino que era necesaria la postulación ordinaria de defensa y representación por profesionales en ejercicio. El TC, partiendo de que la validez de la comparecencia dependía de la calificación del asunto enjuiciado como materia de personal, entendió que la calificación realizada por el Juez como cuestión de personal, corregida por el TSJ, debería haber conducido, con independencia de su corrección, a admitir la posibilidad de que el demandante subsanara el defecto advertido.

Fallo: Otorgar el amparo promovido, y, en su virtud:

$1^{\circ}$ Declarar que ha sido vulnerado el derecho de la demandante a la tutela judicial efectiva (art. 24.1 CE).

$2^{\circ}$ Restablecerla en su derecho y, a tal fin, declarar la nulidad de la Sentencia impugnada, retrotrayendo las actuaciones al momento inmediatamente anterior al dictado de la referida Sentencia para que se concluya la tramitación del recurso de apelación con pleno respeto al derecho fundamental vulnerado.

(Sentencia n. ${ }^{\circ}$ 238/2002, de 9 de diciembre de 2002. Sala Segunda. BOE 10-01-2003. Guillermo Jiménez Sánchez). 


\section{E) Autorización de entrada en lugar cerrado por un Juzgado penal que interfiere con un contencioso- administrativo pendiente}

1. Recurso de amparo 4021/99. Promovido respecto a los Autos de la Audiencia Provincial y de un Juzgado de Instrucción de Ourense que autorizaron al Ayuntamiento a entrar en una finca para demoler una nave industrial. Vulneración del derecho a la tutela judicial efectiva en relación con la autorización de entrada en lugar cerrado por un Juzgado penal que interfiere con un contencioso-administrativo pendiente.

El TC entiende que la marginación o el rechazo de la alegación del recurrente sobre la pendencia del proceso contencioso-administrativo, omitiendo cualquier análisis sobre la aplicabilidad del ya derogado artículo 87.2 de la LOPJ, deben reputarse lesivas del derecho a la tutela judicial efectiva, por cuanto las resoluciones impugnadas interfirieron en la tramitación de una solicitud de suspensión cautelar de la resolución adoptada por el Ayuntamiento ante los órganos contencioso-administrativos, impidiendo que los Tribunales de este orden pudieran dispensar al demandante de amparo la tutela judicial efectiva en toda su extensión.

Fallo: Estimar el recurso de amparo, y, en su virtud:

$1^{\circ}$. Declarar que se ha vulnerado el derecho del recurrente a la tutela judicial efectiva.

$2^{\circ}$. Restablecer al demandante de amparo en el citado derecho, para lo cual se anulan los Autos impugnados.

(Sentencia n. ${ }^{\circ}$ 92/2002, de 22 de abril de 2002. Sala Segunda. BOE 225-2002. Tomás S. Vives Antón).

\section{RECURSO DE AMPARO. INADMISIÓN}

1. Recurso de amparo 1969/98. Promovido por la Universidad Politécnica de Cataluña frente a la Sentencia de la Sala de lo ContenciosoAdministrativo del Tribunal Superior de Justicia de Cataluña que desestimó su demanda contra el Ayuntamiento de Barcelona por liquidación del impuesto sobre bienes inmuebles. Alegada vulneración del derecho a la igualdad: derechos fundamentales de las personas juridicas públicas; exención tributaria de las universidades públicas. 
El TC inadmite el recurso puesto que a las personas públicas se les ha negado por este TC la titularidad del derecho a la igualdad, pues el artículo 14 se refiere a los ciudadanos y no es de aplicación a las personas jurídico-publicas en cuanto tales.

Fallo: Inadmitir el recurso de amparo

(Sentencia n. ${ }^{\circ}$ 239/2001, de 18 de diciembre de 2001. Sala Segunda. BOE 16-6-2002. Tomás S. Vives Antón).

2. Recurso de amparo 2163/98. Promovido por la Universidad de Barcelona respecto a la Sentencia de la Sala de lo Contencioso-Administrativo del Tribunal Superior de Justicia de Cataluña que desestimó su demanda contra el Ayuntamiento de Barcelona por liquidación del impuesto sobre bienes inmuebles. Alegada vulneración del derecho a la igualdad.

Se reproduce la doctrina de la STC 239/2001 en la que se indica que a las personas públicas se les ha negado por este TC la titularidad del derecho a la igualdad, pues el artículo 14 se refiere únicamente a los ciudadanos.

Fallo: Inadmitir el recurso de amparo:

(Sentencia n. ${ }^{\circ}$ 240/2001, de 18 de diciembre de 2001. Sala Segunda. BOE 16-6-2002. Tomás S. Vives Antón).

3. Recurso de amparo 3746/99. Promovido por la Universidad Autónoma de Barcelona frente a la Sentencia de la Sala de lo Contencioso-Administrativo del Tribunal Superior de Justicia de Cataluña que desestimó su recurso contra el Ayuntamiento de Cerdanyola del Vallés por el impuesto sobre bienes inmuebles. Supuesta vulneración del derecho a la igualdad. Remisión a las Sentencias del TC 239/2001 y 240/2001.

El TC remite a la doctrina recogida en las Sentencias 239/2001 y 240/2001, ambas de 18 de diciembre de 2001 (vid. supra), lo que determina la denegación del recurso de amparo.

Fallo: Denegar el amparo solicitado por la Universidad Autónoma de Barcelona.

(Sentencia n. ${ }^{\circ}$ 69/2002, de 21 de marzo de 2002. Sala Primera. BOE 254-2002. Pablo García Manzano). 
RESEÑA DE SENTENCIAS DEL TRIBUNAL CONSTITUCIONAL SOBRE LA ADMINISTRACIÓN LOCAL Y AUTONÓMICA...

\section{POLICÍA}

1. Recurso de inconstitucionalidad 1487/96. Promovido por el Consejo Ejecutivo de la Generalidad de Cataluña contra los artículos 11, 12, 26 y 27 de la Ley 3/1996, de 10 de enero, sobre medidas de control de sustancias químicas catalogadas susceptibles de desvio para la fabricación ilícita de drogas. Competencias en materia de seguridad pública y policía autónoma propia.

La Generalidad de Cataluña no cuestiona que los preceptos recurridos contengan la atribución al Estado de las competencias que se discuten, sino que los mismos no prevean las competencias de la Generalidad derivadas de las competencias asumidas estatutariamente sobre su propia policía autónoma, los Mossos d'Esquadra.

El TC entiende que los preceptos impugnados no infringen las competencias de la Generalidad sobre su policía autónoma.

Fallo: Desestimar el recurso de inconstitucionalidad:

(Sentencia n. ${ }^{\circ}$ 235/2001, de 13 de diciembre. Pleno. BOE 16-1-2002. Vicente Conde Martín de Hijas. Votos particulares que formulan Tomás S. Vives Antón y María Emilia Casas Baamonde, al que se adhieren Pablo García Manzano, Elisa Pérez Vera y Eugeni Gay Montalvo).

\section{URBANISMO}

1. Recurso de inconstitucionalidad 3550/98. Promovido por el Presidente del Gobierno de la Nación contra el artículo único, apartado 1, de la Ley del Parlamento Vasco 11/1998, de 20 de abril, que modificó la Ley de participación de la comunidad en las plusvalías generadas por la acción urbanistica. Competencias sobre urbanismo y derecho de propiedad: cesión del aprovechamiento urbanistico en suelo urbano consolidado (Sentencia 164/2001). Nulidad del precepto autonómico.

El precepto impugnado, al establecer de forma genérica el deber de cesión de aprovechamiento urbanístico en suelo urbano, y extenderlo tanto al suelo urbano «no consolidado» como al «consolidado», contradice las condiciones básicas contenidas en la Ley sobre régimen del suelo y valoraciones (LRSV). El artículo 14.2 c) LRSV únicamente prevé deberes de cesión de aprovechamiento urbanístico en suelo urbano «no conso- 
lidado por la urbanización». En cambio, el artículo 14.1 LRSV se limita a establecer, como deberes específicos de los propietarios de terrenos en suelo urbano «consolidado», el de completar a su costa la urbanización hasta que alcancen la condición de solar y el de edificarlos en los plazos establecidos por el planeamiento. Ello implica que conforme a la LRSV los propietarios de suelo urbano «consolidado» no soportan deberes de cesión o aprovechamiento urbanístico, si siquiera en solares o terrenos ya edificados pero sujetos a obras de rehabilitación.

En el fundamento jurídico 9 de la Sentencia se indica que la declaración de inconstitucionalidad sólo será eficaz pro futuro, esto es, en relación con nuevos supuestos o con los procedimientos administrativos y procedimientos judiciales donde aún no haya recaído resolución firme, tanto por razones de seguridad jurídica como porque de otro modo se distorsionaría gravemente la actividad de gestión urbanística desarrollada al amparo de la norma que se declara inconstitucional.

Fallo: Declarar la inconstitucionalidad y nulidad del art. único, apartado 1, de la Ley del Parlamento Vasco 11/1998, de 20 de abril, de modificación de la Ley 3/1997, de 25 de abril, sólo en la medida en que establece para los propietarios de suelo urbano consolidado por la urbanización un deber de cesión del 10 por 100 del aprovechamiento urbanístico lucrativo o, en el supuesto de obras de rehabilitación, el 10 por 100 del incremento del aprovechamiento urbanístico. Esta declaración de nulidad tendrá los efectos señalados en el fundamento jurídico 9.

(Sentencia n. ${ }^{\circ}$ 54/2002, de 27 de febrero de 2002. Pleno. BOE 3-42002. Elisa Pérez Vera).

\section{MEDIO AMBIENTE}

\section{A) Espacios naturales protegidos}

1. Conflictos positivos de competencia acumulados 1492/95 y 3744/95. Planteados por el Gobierno de la Nación y por el Consejo de Gobierno de la Junta de Andalucía, respecto al Decreto del Consejo de Gobierno de la Junta de Andalucía 418/1994, de 25 de octubre, por el que se aprueba el plan de ordenación de los recursos naturales y el plan rector de uso y gestión del parque natural de Cabo de Gata-Nijar, y la Orden del Ministerio de Agricultura, Pesca y Alimentación de 3 de julio de 1995, por la que se establece la reserva marina de Cabo de Gata-Níjar. Competencias sobre medio 
RESEÑA DE SENTENCIAS DEL TRIBUNAL CONSTITUCIONAL SOBRE LA ADMINISTRACIÓN LOCAL Y AUTONÓMICA...

ambiente, pesca marítima y el mar territorial. Delimitación del ámbito de vigencia de varios preceptos autonómicos.

En cuanto a lo que deba entenderse por territorio autonómico, tanto la jurisprudencia del Tribunal Supremo, como la doctrina del Consejo de Estado, han sostenido respecto a los puertos y a la zona marítimo-terrestre que uno y otra forman parte inequívoca del territorio municipal en que están enclavados, basándose en que legalmente todo el territorio nacional se divide en términos municipales, de forma que no pueden quedar espacio territoriales excluidos de ellos; parece claro que la misma doctrina hay que aplicar a la división del territorio nacional en Comunidades Autónomas. Distinto es el caso del mar territorial, donde excepcionalmente pueden ejercerse competencias autonómicas, eventualidad ésta que dependerá, bien de un explícito reconocimiento estatutario, bien de la naturaleza de la competencia tal como resulta de la interpretación del bloque de la constitucionalidad.

El TC señala que aunque las competencias de la Junta de Andalucía en materia de espacios naturales protegidos no alcanzan, por regla general, al mar territorial, las circunstancias y características específicas del espacio a proteger pueden demandar, en ocasiones excepcionales, que el mismo se extienda en alguna medida sobre el mar territorial, singularmente cuando así venga exigido por la continuidad y unidad de dicho espacio físico.

Fallo: $1^{\circ}$. Estimar parcialmente el conflicto positivo de competencia núm. 1492/95, promovido por el Gobierno de la Nación y, en consecuencia:

a) Declarar que corresponden al Estado las competencias contenidas en los arts. 18.5, 138, 139.3, 140, 142, 145, 147, 151, 152, 153, 156, 254.2.e) y g). 255.1.c), salvo el inciso «y el marisqueo», y e); y 255.2.e), y f) del Anexo 1; y en los arts. 45.1, 2, 3, 6, 8 y 9; 46.2 y 73 a) y c), salvo el inciso «el marisqueo deportivo», del Anexo 2 del Decreto del Consejo de Gobierno de la Junta de Andalucía 418/1994, de 25 de octubre, por el que se aprueba el plan de ordenación de los recursos naturales y el plan rector de uso y gestión del parque natural de Cabo de Gata-Níjar.

b) Declarar que dichos preceptos no son de aplicación en el tramo del límite este y sur del parque natural Cabo de Gata-Níjar, que comprende una franja marina de una milla de anchura, paralela a la línea de costa descrita, que coincide aproximadamente con la cota batimétrica de 50 metros (Anexo III del Decreto 418/1994) y que se extiende al mar territorial.

c) Desestimar el conflicto en todo lo demás. 
$2^{\circ}$. Desestimar el conflicto positivo de competencia n. ${ }^{\circ} 3744 / 95$, promovido por la Junta de Andalucía en relación con la Orden del Ministerio de Agricultura, Pesca y Alimentación de 3 de julio de 1995, por la que se establece la reserva marina de Cabo de Gata-Nijar.

(Sentencia n..$^{\circ}$ 38/2002, de 14 de febrero de 2002. Pleno. BOE 14-32002. Manuel Jiménez de Parga y Cabrera. Voto particular que formula Pablo García Manzano).

2. Recursos de inconstitucionalidad 3492/95 y 3672/95 (acumulados). Promovidos por el Gobierno y el Parlamento de la Comunidad Autónoma de las Illes Balears contra la Ley 26/1995, de 31 de julio, por la que se declara reserva natural las Salinas de Ibiza ( Ses Salines»), las Islas des Freus y las Salinas de Formentera. Competencias sobre medio ambiente y espacios naturales protegidos.

La Ley recurrida, en cuanto que procede a declarar reserva natural a un determinado espacio físico, estableciendo el régimen jurídico de protección que le es propio, se incardina, desde la perspectiva del orden constitucional de distribución de competencias, en la materia de espacios naturales protegidos.

La CA de las Illes Balears tiene la competencia de desarrollo legislativo y la ejecución en el marco de la legislación básica del Estado en materia de protección del medio ambiente, normas adicionales de protección, espacios naturales protegidos y ecología. Y habida cuenta de esta competencia, la declaración como reserva natural del espacio físico al que se refiere la Ley impugnada corresponde a la Comunidad Autónoma, sin que pueda oponerse nada en contrario por el hecho de que dicho espacio se localice en todo o en parte en el dominio público marítimo-terrestre.

Fallo: Declarar inconstitucional y nula la Ley impugnada.

(Sentencia n. ${ }^{\circ}$ 97/2002, de 25 de abril de 2002. Sala Primera. BOE 225-2002. Javier Delgado Barrio).

\section{B) Residuos industriales}

1. Conflicto positivo de competencia 2836/93. Planteado por el Consejo Ejecutivo de la Generalidad de Cataluña frente a la Orden del Ministerio de Obras Públicas y Transportes de 22 de marzo de 1993 (artículos 4, 5, 6, 7, 8, 9, 10, 11, 12 y 14), por la que se regula la concesión de ayudas previstas en el Plan nacional de resi- 
RESEÑA DE SENTENCIAS DEL TRIBUNAL CONSTITUCIONAL SOBRE LA ADMINISTRACIÓN LOCAL Y AUTONÓMICA...

duos industriales para ese año. Competencias sobre medio ambiente.

El TC entiende que la mencionada Orden, en algunos aspectos vulnera las competencias de la CA de Cataluña en materia de medio ambiente, en la medida en que la regulación objetada excede de lo que puede considerarse como normativa básica y atribuye a órganos estatales funciones ejecutivas que corresponden a la Generalidad de Cataluña.

Fallo: Estimar parcialmente el conflicto positivo de competencia y, en consecuencia:

$1^{\circ}$. Declarar que corresponden a la Generalidad de Cataluña las competencias controvertidas contenidas en los arts. $4.2 ; 5 ; 6 ; 7.2 ; 8 ; 9 ; 11 ; 12$ y 14 de la Orden impugnada.

$2^{\circ}$. Desestimar el conflicto en todo lo demás.

(Sentencia n. ${ }^{\circ}$ 126/2002, de 23 de mayo de 2002. Pleno. BOE 19-62002. Eugeni Gay Montalvo).

\section{B) Caza y pesca de especies protegidas}

1. Recurso de inconstitucionalidad 2989/95. Promovido por el Presidente del Gobierno, en relación con diversos preceptos de la Ley de la Asamblea de la Región de Murcia 7/1995, de 21 de abril, de la fauna silvestre, caza y pesca fluvial (en concreto, respecto de los artículos 27, párrafo primero, 103.1 y 113.c).Competencias sobre medio ambiente: especies protegidas, infracciones y sanciones por caza. Nulidad parcial de los preceptos autonómicos.

El TC estima parcialmente el recurso en tanto en cuanto los preceptos de la Ley murciana vulneran la distribución competencial contenida en el artículo 149.1.23 CE, que asigna al Estado la competencia exclusiva para dictar la legislación básica sobre protección del medio ambiente, sin perjuicio de las facultades de las Comunidades Autónomas de establecer normas adicionales de protección, en cuanto que los preceptos declarados nulos se oponen a las previsiones de la normativa básica estatal contenida, de un lado, en la Ley 4/1989, de 27 de marzo, de conservación de los espacios naturales y de la flora y fauna silvestre (en adelante, LCEN) y, de otro lado, del complementario RD 118/1989, de 15 de septiembre, por el que se determinan las especies objeto de caza 
y pesca comercializables, y se dictan normas al respecto, en desarrollo del art. 34.c) LCEN.

Fallo: Estimar parcialmente el recurso de inconstitucionalidad, y en consecuencia:

$1^{\circ}$. Declarar que es inconstitucional y nulo el párrafo primero del artículo 27 de la mencionada Ley, en cuanto establece que podrán ser objeto de comercialización, en vivo o en muerto, las siguientes especies incluidas en el anexo III de la referida Ley: paloma bravía, tórtola común, tórtola turca, zorzal real, zorzal común, zorzal alirrojo, zorzal charlo, estornino pinto, estornino negro, jilguero, pardillo, verderón, verdecillo (entre las especies cazables y capturables), y el «black-bass» o perca americana (entre las especies pescables).

$2^{\circ}$. Declarar inconstitucional y nulo el artículo 103.1 de la referida Ley autonómica en cuanto establece un plazo de prescripción de tres años para las infracciones administrativas muy graves previstas en el art. 112, números 1, 2 y 4 de dicha Ley, si bien con la precisión, en cuanto a este último número, efectuada en el Fundamento Jurídico 10 de esta Sentencia.

$3^{\circ}$. Declarar inconstitucional y nulo el artículo 113 c) de la Ley autonómica impugnada, exclusivamente en cuanto señala como cuantía mínima de la multa para las infracciones muy graves la cantidad de un millón una pesetas (1.000.001 pesetas), con la misma previsión, en cuanto a la infracción muy grave del art. 112.4 de dicha Ley, contenida en el Fundamento jurídico 10 de esta Sentencia.

(Sentencia n. ${ }^{\circ}$ 166/2002, de 18 de septiembre de 2002. Pleno. BOE 910-2002. Pablo García Manzano).

\section{LEYES DE ACOMPAÑAMIENTO}

1. Recurso de inconstitucionalidad 1135/95. Promovido por el Consejo de Gobierno de la Comunidad Autónoma de La Rioja respecto de la disposición adicional octava de la Ley 42/1994, de 30 de diciembre, de Medidas Fiscales, Administrativas y del Orden Social, que dispone un reembolso tributario estatal a residentes en la Unión Europea que operan en el País Vasco o Navarra. Principios de seguridad jurídica e interdicción de la arbitrariedad; vulneración de la igualdad tributaria, territorial y unidad de mercado. Nulidad del precepto. 
RESEÑA DE SENTENCIAS DEL TRIBUNAL CONSTITUCIONAL SOBRE LA ADMINISTRACIÓN LOCAL Y AUTONÓMICA...

Según el TC, a diferencia de otras medidas tributarias localizadas en una parte del territorio nacional (por ejemplo, las previstas para Ceuta y Melilla, consecuencia del infradesarrollo regional, o para Canarias, resultado de su insularidad), la ayuda ahora analizada carece de justificación alguna que la legitime desde el punto de vista tributario, pues no responde a ninguna clase de política sectorial -social o económica-, cual podría ser el paliar una particular situación de crisis o deterioro industrial, optimizando el crecimiento económico y favoreciendo el desarrollo regional. La norma no supera el juicio de constitucionalidad en el análisis de sus consecuencias tributarias, por ser no sólo irrazonables sino también desproporcionadas con la finalidad perseguida y, en consecuencia, negadoras de una justificación que permita a los poderes públicos abdicar de la recaudación impositiva.

Tampoco supera la norma impugnada el juicio de constitucionalidad desde la perspectiva de las libertades de empresa, residencia y circulación.

Fallo: Declarar la inconstitucionalidad y consiguiente nulidad de la disposición adicional octava de la Ley impugnada.

(Sentencia n. ${ }^{\circ}$ 96/2002, de 25 de abril de 2002. Pleno. BOE 22.5.2002. Pablo Cachón Villar. Votos particulares que formulan, por un lado, Tomás S. Vives Antón y María Emilia Casas Baamonde al que se adhieren Pablo García Manzano y Elisa Pérez Vera y, por otro lado, Eugeni Gay Montalvo).

2. Recurso de inconstitucionalidad 1251/97. Promovido por el Consejo Ejecutivo de la Generalidad de Cataluña contra los artículos 24 y 166 de la Ley 13/1996, de 30 de diciembre, de medidas fiscales, administrativas y del orden social. La Sentencia aborda dos cuestiones distintas: A) Competencias sobre juego: tasas por expedición de guías de circulación para máquinas recreativas y de azar «en todo el territorio nacional» B) Competencias en materia de ordenación del territorio y urbanismo; principio de autonomía local; planeamiento en las zonas de servicio de los aeropuertos de interés general, y licencias de obra. Nulidad parcial e interpretación de los preceptos estatales impugnados.

A) En relación con el artículo 24: Según el orden de distribución de competencias en materia de juego, las Comunidades Autónomas son las Administraciones competentes en sus respectivos territorios para la expedición de las guías de circulación para máquinas recreativas y de azar, por cuanto disponen de la potestad normativa para regular las características 
de fabricación y homologación de este instrumento de juego. Siguiendo el principio según el cual la competencia para crear tasas por servicios deriva necesariamente de la que se ostenta para organizar los servicios públicos correspondientes, la competencia para crear la tasa por expedición de las referidas guías de circulación corresponde a las Comunidades Autónomas y no al Estado; por lo que el inciso «en todo el territorio nacional» del título del artículo 24 y de su apartado uno de la Ley 13/1996 debe declararse inconstitucional. El Estado ostenta la competencia para la expedición de las guías y la creación de la correspondiente tasa exclusivamente en las ciudades de Ceuta y Melilla.

Dado que la extensión territorial del juego no atribuye competencia al Estado, el carácter pluriautonómico de la actividad de las empresas fabricantes e importadoras de máquinas recreativas y de azar no otorga al Estado una competencia administrativa respecto de ellas, y por lo tanto tampoco una potestad para convertirlas en sujetos pasivos de la tasa por expedición de las guías de circulación que crea el artículo 24.3 de la Ley 13/1996. La competencia del Estado para la expedición de guías y la creación de la correspondiente tasa se circunscribe exclusivamente a las ciudades de Ceuta y Melilla, de ahí que el Estado no pueda determinar el sujeto pasivo de dicha tasa acudiendo a un criterio que desborda aquel ámbito territorial, tal como hace el apartado tres del artículo 24 de la Ley.

B) En relación con el artículo 166: En su párrafo 3 este artículo 166 establece que «las obras de nueva construcción, reparación y conservación que se realicen en el ámbito del aeropuerto y su zona de servicio por AENA no estarán sometidas a los actos de control preventivo municipal a que se refiere el artículo 84.1. b) de la LRBRL, por constituir obras públicas de interés general». Como la exclusión de los actos de control preventivo municipal a que se refiere el art. 84.1.b) LRBRL es absoluta, alcanzando incluso a la intervención por vía de informe el TC entiende que en este caso la garantía institucional de la autonomía local no se respeta.

Fallo: Estimar parcialmente el presente recurso de inconstitucionalidad, y en consecuencia, declarar:

a) Que es inconstitucional y nulo el inciso «en todo el territorio nacional», del título del art. 24 de la Ley y de su apartado uno.

b) Que es inconstitucional y nulo el apartado tres del art. 24 de la Ley.

c) Que el art. 166.1 de la Ley no vulnera el orden constitucional de competencias interpretado en el sentido señalado en el fundamento jurídico 8 , párrafo penúltimo. 
RESEÑA DE SENTENCIAS DEL TRIBUNAL CONSTITUCIONAL SOBRE LA ADMINISTRACIÓN LOCAL Y AUTONÓMICA...

d) Que el art. 166.2, párrafo segundo, inciso referente a la formulación del plan especial por Aeropuertos Españoles y Navegación Aérea, no vulnera el orden constitucional de competencias, interpretado en el sentido señalado en el fundamento jurídico 11, párrafo penúltimo.

e) Que es inconstitucional y nulo el art. 166.3 de la Ley.

f) Desestimar el recurso de inconstitucionalidad en todo lo demás.

(Sentencia n..$^{\circ}$ 204/2002, de 31 de octubre de 2002. Pleno. BOE 20-112002. Vicente Conde Martín de Hijas. Voto particular de Pablo García Manzano).

\section{PENSIONES}

1. Conflictos positivos de competencia 1207/99 y 1208/99. Planteados por el Gobierno de la Nación frente a los Decretos de la Junta de Andalucía 284/1998, de 29 de diciembre, y 62/1999, de 9 de marzo, que establecen ayudas económicas complementarias, de carácter extraordinario, a favor de los pensionistas por jubilación e invalidez en sus modalidades no contributivas. Competencias sobre seguridad social y asistencia social.

La cuestión litigiosa se circunscribía a determinar si los Decretos impugnados vulneraban las competencias estatales sobre la «legislación básica y régimen económico de la Seguridad Social» (art. 149.1.17 CE), así como las relativas a la «regulación de las condiciones básicas que garanticen la igualdad de todos los españoles en el ejercicio de los derecho y en el cumplimiento de los deberes constitucionales» (art. 149.1.1 CE); o, si por el contrario, al tratar de paliar los Decretos en cuestión situaciones de necesidad en que se encontraban sus destinatarios (jubilados de más de 65 años e inválidos en grado superior al $65 \%$, beneficiarios de pensiones no contributivas de jubilación e invalidez, cuyas percepciones por tal concepto han sido actualizadas en 1999 por debajo de IPC y se encuentran situadas por debajo del salario mínimo interprofesional), se trata de una actuación incluida en el ámbito de la asistencialidad que se conecta con la competencia exclusiva de la CA de Andalucía en materia de «asistencia y servicios sociales» (art. 13.33.EAA).

El TC entiende que existen diferencias relevantes entre estas ayudas y las pensiones no contributivas de invalidez y jubilación incluidas en el sistema de la Seguridad Social: su carácter complementario de las mencio- 
nadas pensiones de la Seguridad Social; su carácter extraordinario, que limitan en el tiempo el derecho a la percepción; la inexistencia de módulos de actualización de los auxilios, consecuencia de lo anterior; y su abono a cargo de los presupuestos autonómicos.

Por lo anterior el TC entiende que los auxilios económicos objeto de esta controversia competencial tienen una naturaleza específica y distinta de las técnicas prestacionales de la Seguridad Social, de modo que se incardinan en la materia «asistencia social», configurada como una «técnica de protección fuera del sistema de la Seguridad Social con caracteres propios que la separan de otros afines o próximos a ella» (STC 171/1998, de 23 de julio, FJ 3).

Asimismo concluye el Alto Tribunal que una vez desestimado que los auxilios autonómicos supongan un incremento de las pensiones del ámbito de la Seguridad Social, cabe concluir que tampoco se han vulnerado las condiciones básicas que garanticen la igualdad en esta materia.

Fallo: Desestimar los conflictos positivos de competencia promovidos por el Gobierno de la Nación frente a los Decretos impugnados, y declarar que la competencia controvertida corresponde a la Comunidad Autónoma.

(Sentencia n. ${ }^{\circ}$ 239/2003, de 11 de diciembre de 2002. Pleno. BOE 10.01.2003. Eugeni Gay Montalvo. Voto particular de Vicente Conde Martín de Hijas al que se adhiere Javier Delgado Barrio; y voto particular que formula don Roberto García-Calvo y Montiel; a ambos votos particulares se adhiere Manuel Jiménez de Parga y Cabrera).

\section{FORMACIÓN CONTINUA DE TRABAJADORES OCUPADOS}

1. Recurso de inconstitucionalidad 938/93 y conflicto positivo de competencias 1176/93 (acumulado). Promovido por el Consejo Ejecutivo de la Generalidad de Cataluña en relación con la disposición adicional vigesimotercera de la Ley 39/1992, de 29 de diciembre, de Presupuestos Generales del Estado para 1993 y con el Acuerdo tripartito en materia de formación continua de los trabajadores ocupados, suscrito en Madrid el 22 de diciembre de 1992 entre el Gobierno y las organizaciones sindicales y empresariales. Competencias sobre legislación laboral, educación y formación profesional, fondos de empleo, y ordenación de la economía. 
RESEÑA DE SENTENCIAS DEL TRIBUNAL CONSTITUCIONAL SOBRE LA ADMINISTRACIÓN LOCAL Y AUTONÓMICA...

En relación con el Acuerdo Tripartito impugnado, el TC entiende, con carácter general, que desapodera a la Generalidad de Cataluña de la competencia ejecutiva en materia de formación continua de los trabajadores ocupados, dentro de su ámbito territorial, al sustituirse el sistema de gestión pública de esta modalidad formativa que venía rigiendo en la materia, y sobre el que se había operado el traspaso de servicios y consiguiente asunción de la competencia estatutaria, por un sistema de gestión centralizada encomendado en su integridad a los interlocutores sociales integrados en el ente paritario estatal, y en cuya gestión no participa en modo alguno la Administración autonómica.

En relación con la disposición adicional vigesimotercera de la Ley 39/1992, la reivindicación competencial se circunscribe al segundo párrafo de la misma, es decir, se impugna el criterio de que la financiación contemplada en dicha disposición adicional se ponga a disposición del ente paritario de ámbito estatal de las representaciones sindicales y empresariales. El precepto impugnado es la traducción presupuestaria del soporte financiero de las acciones formativas acogidas al sistema de formación continua de los trabajadores ocupados, que trae causa del Acuerdo interprofesional sobre la materia y el subsiguiente Acuerdo tripartito, en el que participó el Gobierno de la Nación, por el que se determina la puesta a disposición del ente paritario estatal de la correspondiente dotación económica, es decir, de la íntegra cantidad con la que se subvencionan dichas acciones de formación continua, produciéndose así la exclusión de tales recursos o cantidades de su oportuna gestión y administración por quien, como la Generalidad de Cataluña, ostenta la titularidad de la función ejecutiva en dicha materia, al no territorializarse dichas acciones. Por ello, el TC, en concordancia con lo antes expuesto, procede a declarar la inconstitucionalidad de la citada disposición adicional vigesimotercera, en su párrafo segundo, por vulnerar el orden constitucional de distribución de competencias, al excluir a la Generalidad de Cataluña de la percepción de los correspondientes fondos públicos destinados a financiar la formación continua en su ámbito territorial.

Fallo: $1^{\circ}$. Estimar parcialmente el conflicto positivo de competencia promovido contra el Acuerdo tripartito en materia de formación continua de trabajadores ocupados, y en su virtud:

a) Declarar que la titularidad de la competencia de ejecución en la materia controvertida corresponde a la Generalidad de Cataluña.

b) Declarar, asimismo, que vulneran el orden constitucional de distribución de competencias y son, por ello, inaplicables en Cataluña, las siguientes determinaciones del mencionado Acuerdo tripartito: 
- Acuerdo primero, apartado 2, en el inciso que dice: «el Instituto Nacional de Empleo transferirá al Ente Paritario Estatal, que las partes firmantes del Acuerdo Nacional sobre Formación Continua constituyan y designen, las cantidades correspondientes al citado 0,10 por 100 de la cuota de Formación Profesional».

- Acuerdo tercero, párrafo primero, inciso inicial, a cuyo tenor: «El Gobierno y las organizaciones firmantes convienen en que todos los aspectos relativos a la organización, gestión, distribución de fondos, $\mathrm{o}$, en su caso, ejecución de las acciones formativas y justificación de las mismas, corresponden a los interlocutores sociales a través de los correspondientes entes de composición paritaria».

- Acuerdo tercero, párrafo segundo, en los «guiones» segundo, cuarto $\mathrm{y}$ quinto.

c) Desestimar el conflicto competencial en todo lo demás.

$2^{\circ}$. Estimar el recurso de inconstitucionalidad promovido por el Consejo Ejecutivo de la Generalidad de Cataluña contra la disposición adicional vigesimotercera de la Ley 39/1992, de 29 de diciembre, de Presupuestos Generales del Estado para 1993, y, en consecuencia, declarar que el párrafo segundo de dicha disposición no se ajusta al orden constitucional de distribución de competencias y es, por ello, inaplicable en el ámbito territorial de Cataluña.

(Sentencia n. ${ }^{\circ}$ 95/2002, de 25 de abril de 2002. Sala Primera. BOE 225-2002. Pablo García Manzano. Votos particulares que formulan Pablo García Manzano y María Emilia Casas Baamonde; Vicente Conde Martín de Hijas; Guillermo Jiménez Sánchez; y Roberto García-Calvo y Montiel.)

2. Recurso de inconstitucionalidad 1026/95. Promovido por la Junta de Galicia contra la disposición adicional segunda de la Ley 41/1994, de 30 de diciembre, de presupuestos generales del Estado para 1995, sobre financiación de acciones de formación continua. Competencias sobre legislación laboral, educación y formación profesional, fondos de empleo, y ordenación de la economía (STC 95/2002). Nulidad e interpretación del precepto.

El TC reiterando la doctrina recogida en su Sentencia 95/2002 (vid. supra) afirma que el principio recogido en el primer inciso del párrafo segundo de la Disposición adicional recurrida, según el cual los fondos destinados a formación se pondrán «a disposición de la Fundación para la 
Formación Continua», vulnera las competencias de la Junta de Galicia, pues corresponde a esta Comunidad Autónoma gestionarlos tras su puesta a disposición por el Estado de acuerdo con los criterios objetivos que determinen la territorialización correspondiente entre las Comunidades Autónomas competentes.

Sin embargo, este criterio sólo es extensivo al primer inciso del párrafo segundo, ya que su segundo inciso se refiere a un aspecto diferente: el de la exclusión de la puesta a disposición de la Fundación para la Formación Continua de una parte de los fondos presupuestados, los cuales, por ir destinados a la formación continua de las AAPP, se financiarán al amparo de la Ley 9/1987, de 12 de junio, de órganos de representación, determinación de las condiciones de trabajo y participación del personal al servicio de las Administraciones Públicas. La previsión de este segundo inciso, relativa al destino de fondos presupuestarios del Estado para la formación continua en las AAPP, en lo referente a su dimensión normativa, no resulta alcanzada por el reproche de este recurso de inconstitucionalidad, que se ciñe a la dimensión ejecutiva o aplicativa, respecto de la cual este segundo inciso nada dice, por lo que no puede ser considerado contrario al orden constitucional de competencias siempre que se interprete que dichos fondos han de distribuirse entre las Comunidades Autónomas según criterios objetivos de reparto.

Fallo: Estimar parcialmente el recurso de inconstitucionalidad, y, en consecuencia:

$1^{\circ}$ Declarar que son contrarias al orden constitucional de competencias $\mathrm{y}$, por tanto, inconstitucionales y nulas, en los términos y con el alcance expresados en el fundamento jurídico 9 de esta Sentencia, las facultades que el párrafo segundo de dicha disposición adicional atribuye a la Fundación para la Formación Continua y a la Comisión Tripartita de Seguimiento.

$2^{\circ}$. Que el párrafo tercero de la disposición adicional no es inconstitucional interpretado en el sentido indicado en el penúltimo párrafo del fundamento jurídico 8 .

$3^{\circ}$. Desestimar el recurso en todo lo demás.

(Sentencia n. ${ }^{\circ}$ 190/2002, de 17 de octubre de 2002. Pleno. BOE 12-112002. Guillermo Jiménez Sánchez. Votos particulares que formulan Vicente Conde Martín de Hijas y Guillermo Jiménez y Sánchez). 